Journal of Mathematics and Informatics

Vol. 8, 2017, 1-6

ISSN: 2349-0632 (P), 2349-0640 (online)

Published 21 June 2017

www.researchmathsci.org

DOI: http://dx.doi.org/10.22457/jmi.v8a1

Journal of

Mathematics and

Informatics

\title{
Common Fixed Points of Occasionally Weakly Compatible in Intuitionistic Fuzzy Metric Space
}

\author{
Preeti Sengar ${ }^{1}$,Suman Jain ${ }^{2}$, Aklesh Pariya ${ }^{3}$ and V.H.Badshah ${ }^{4}$ \\ ${ }^{1,4}$ School of Studies in Mathematics, Vikram University, Ujjain (M.P.) India \\ ${ }^{2}$ Department of Mathematics, Govt. College, Kalapipal (M.P.) India \\ ${ }^{3}$ Department of Applied Mathematics, Medi-caps University, Indore (M.P.) India
}

Received 5 May 2017; accepted 19 June 2017

Abstract. In this paper, we prove some common fixed point theorem for occasionally weakly compatible maps in intuitionistic fuzzy metric spaces satisfying implicit relation. Our result extends and generalizes the recent results of Manro et al. [13, 14].

Keywords: Fixed point theory, intuitionistic fuzzy metric space

AMS Mathematics Subject Classification (2010): 47H10, 54H 25

\section{Introduction and preliminaries}

The notion of fuzzy sets was introduced by Zadeh [18].Since then; to use this concept in topology and analysis many authors have expansively developed the theory of fuzzy sets and applications. Atanassov [6] introduces the notion of intuitionistic fuzzy sets by generalizing the notion of fuzzy set by treating membership as a fuzzy logical value rather than a single truth value. For an intuitionistic set the logical value has to be consistent (in the sense $\mu_{A}(x)+\gamma_{A}(x) \leq 1$ ), where $\mu_{A}(x)$ and $\gamma_{A}(x)$ denotes degree of membership and degree of non-membership, respectively. All results which hold of fuzzy sets can be transformed intuitionistic fuzzy sets but converse need not be true.

Alaca et al. [1] using the idea of intuitionistic fuzzy sets, they defines the notion of intuitionistic fuzzy metric spaces as Park [15] with the help of continuous t-norm and continuous t-conorm as a generalization of fuzzy metric space due to Kromosil and Michalek [12]. Further, they introduced the notion of Cauchy sequences in an intuitionistic fuzzy metric spaces and proved the well-known fixed point theorems of Banach [7] and Edelstein [8] extended to intuitionistic fuzzy metric spaces with the help to Grabiec [9]. Al-Thagafi and Shazad [3,4] introduced the notion of occasionally weakly compatible (owc) maps and gave some remarks on owc maps in metric spaces.

Definition 1.1. [2]A 5-tuple $(\mathrm{X}, \mathrm{M}, \mathrm{N}, *, \diamond)$ is said to be an intuitionistic fuzzy metric space if $\mathrm{X}$ is an arbitrary set,* is a continuous t-norm, $\diamond$ is a continuous t-co norm and $\mathrm{M}, \mathrm{N}$ are fuzzy sets on $\mathrm{X}^{2} \times[0, \infty)$ satisfying the following conditions:

(i) $\mathrm{M}(\mathrm{x}, \mathrm{y}, \mathrm{t})+\mathrm{N}(\mathrm{x}, \mathrm{y}, \mathrm{t}) \leq 1$ for all $\mathrm{x}, \mathrm{y} \in \mathrm{X}$ and $\mathrm{t}>0$;

(ii) $M(x, y, 0)=0$ for all $x, y \in X$;

(iii) $\mathrm{M}(\mathrm{x}, \mathrm{y}, \mathrm{t})=1$ for all $\mathrm{x}, \mathrm{y} \in \mathrm{X}$ and $\mathrm{t}>0$, if and only if 
Preeti Sengar, Suman Jain, Aklesh Pariya and V.H.Badshah $\mathrm{x}=\mathrm{y}$;

(iv) $M(x, y, t)=M(y, x, t)$ for all $x, y \in X$ and $t>0$;

(v) $M(x, y, t) * M(y, z, s) \leq M(x, z, t+s)$

for all $\mathrm{x}, \mathrm{y}, \mathrm{z} \in \mathrm{X}$ and $\mathrm{s}, \mathrm{t}>0$;

(vi) for all $\mathrm{x}, \mathrm{y} \in \mathrm{X}, \mathrm{M}(\mathrm{x}, \mathrm{y}, \cdot):[0, \infty) \rightarrow[0,1]$ is left continuous;

(vii) $\lim _{\mathrm{t} \rightarrow \infty} \mathrm{M}(\mathrm{x}, \mathrm{y}, \mathrm{t})=1$ for all $\mathrm{x}, \mathrm{y} \in \mathrm{X}$ and $\mathrm{t}>0$;

(viii) $\mathrm{N}(\mathrm{x}, \mathrm{y}, 0)=1$ for all $\mathrm{x}, \mathrm{y} \in \mathrm{X}$;

(ix) $\mathrm{N}(\mathrm{x}, \mathrm{y}, \mathrm{t})=0$ for all $\mathrm{x}, \mathrm{y} \in \mathrm{X}$ and $\mathrm{t}>0$, if and only if $\mathrm{x}=\mathrm{y}$

(x) $N(x, y, t)=N(y, x, t)$ for all $x, y \in X$ and $t>0$;

(xi) $N(x, y, t) \diamond N(y, z, s) \geq N(x, z, t+s)$

for all $\mathrm{x}, \mathrm{y}, \mathrm{z} \in \mathrm{X}$ and $\mathrm{s}, \mathrm{t}>0$;

(xii) for all $\mathrm{x}, \mathrm{y} \in \mathrm{X}, \mathrm{N}(\mathrm{x}, \mathrm{y}, \cdot):[0, \infty) \rightarrow[0,1]$ is right continuous;

(xiii) $\lim _{\mathrm{t} \rightarrow \infty} \mathrm{N}(\mathrm{x}, \mathrm{y}, \mathrm{t})=0$ for all $\mathrm{x}, \mathrm{y} \in \mathrm{X}$ and $\mathrm{t}>0$;

Then $(M, N)$ is called an intuitionistic fuzzy metric on $X$. The function $M(x, y, t)$ and $\mathrm{N}(\mathrm{x}, \mathrm{y}, \mathrm{t})$ denote the degree of nearness and degree of non-nearness between $\mathrm{x}$ and $\mathrm{y}$ with respect to $t$, respectively.

Remark 1.1. [2] In intuitionistic fuzzy metric space $X, M(x, y, \cdot)$ is non decreasing and $\mathrm{N}(\mathrm{x}, \mathrm{y}, \cdot)$ is non increasing for all $\mathrm{x}, \mathrm{y} \in \mathrm{X}$.

Example 1.1. [1] Let $(X, d)$ be a metric space. Define t-norm $a * b=\min \{a, b\}$ and $t-$ conorm $\mathrm{a} \diamond \mathrm{b}=\max \{\mathrm{a}, \mathrm{b}\}$ and let $\mathrm{M}_{\mathrm{d}}$ and $\mathrm{N}_{\mathrm{d}}$ be fuzzy sets on $\mathrm{X}^{2} \times[0, \infty)$ defined as follows:

$$
M_{d}(x, y, t)=\frac{t}{t+d(x, y)}, N_{d}(x, y, t)=\frac{d(x, y)}{t+d(x, y)} .
$$

Then $\left(X, M_{d}, N_{d}, *, \diamond\right)$ is an intuitionistic fuzzy metric space induced by the metric $\mathrm{d}$ is called the standard intuitionistic fuzzy metric space. It is obvious that $\mathrm{N}(\mathrm{x}, \mathrm{y}, \mathrm{t})=1-\mathrm{M}(\mathrm{x}$, $y, t)$.

Definition 1.2. [11] A point $x \in X$ is called a coincidence point of a pair of self mappings $(A, S)$ defined on a non-empty set $X$ iff $A x=S x$. we shall call $w=A x=S x$, a point of coincidence of $\mathrm{A}$ and $\mathrm{S}$.

Definition 1.3. $[3,4]$ Two self maps $f$ and $g$ of a set $X$ are called occasionally weakly compatible iff there is a point $x \in X$ which is coincidence point of $f$ and $g$ at which $f$ and $g$ commute.

Lemma 1.1. [11] Let $X$ be a set and $A$ and $S$ are occasionally weakly compatible self mappings on $X$. If $A$ and $S$ have a unique point of coincidence $w=A x=S x$, then $w$ is the unique common fixed point of $\mathrm{A}$ and $\mathrm{S}$.

\section{Implicit relation}

Let $\mathrm{M}_{6}$ be the set of all real-valued continuous functions $\phi$ and $\psi:[0,1]^{6} \rightarrow \mathrm{R}$,nondecreasing in the first argument and satisfying the following conditions:

$\left(\mathrm{F}_{1}\right) \phi(\mathrm{u}, \mathrm{u}, 1,1, \mathrm{u}, \mathrm{u}) \geq 0 \Rightarrow \mathrm{u} \geq 1$ 
Common Fixed Points of Occasionally Weakly Compatible in Intuitionistic Fuzzy Metric Space

$\left(\mathrm{F}_{2}\right) \phi(\mathrm{u}, 1, \mathrm{u}, 1, \mathrm{u}, 1) \geq 0 \Rightarrow \mathrm{u} \geq 1$

$\left(\mathrm{F}_{3}\right) \phi(\mathrm{u}, \mathrm{u}, \mathrm{u}, 1,1,1) \geq 0 \Rightarrow \mathrm{u} \geq 1$

(F) $\psi(\mathrm{u}, \mathrm{u}, 0,0, \mathrm{u}, \mathrm{u}) \leq 0 \Rightarrow \mathrm{u} \leq 0$;

(F5) $\psi(\mathrm{u}, 0, \mathrm{u}, 0, \mathrm{u}, 0) \leq 0 \Rightarrow \mathrm{u} \leq 0$;

(F6) $\psi(\mathrm{u}, \mathrm{u}, \mathrm{u}, 0,0,0) \leq 0 \Rightarrow \mathrm{u} \leq 0$; for all $\mathrm{u} \geq 0$.

In this paper, we prove some common fixed point theorems in intuitionistic fuzzy metric space for occasionally weakly compatible mappings satisfying implicit relation. Our results generalize the recent result of Manro et al. [13, 14].

Theorem 2.1. Let A, B, S and T be four self-mappings of an intuitionistic fuzzy metric space $(X, M, N, *, \diamond)$ satisfying the following conditions:

for any $\mathrm{x}, \mathrm{y} \in \mathrm{X}, \phi, \psi \in \mathrm{M}_{6}$ and for all $\mathrm{t}>0$, such that

$$
\begin{gathered}
\phi\left\{\begin{array}{l}
M(A x, B y, t), M(S x, T y, t), M(S x, A x, t), \\
M(T y, B y, t), M(A x, T y, t), M(B y, S x, t)
\end{array}\right\} \geq 0 \\
\psi\left\{\begin{array}{l}
N(A x, B y, t), N(S x, T y, t), N(S x, A x, t), \\
N(T y, B y, t), N(A x, T y, t), N(B y, S x, t)
\end{array}\right\} \leq 0
\end{gathered}
$$

If the pairs (A, S) and (B, T) are each occasionally weakly compatible, then $\mathrm{A}, \mathrm{B}, \mathrm{S}$ and $\mathrm{T}$ have a unique common fixed point.

Proof: Since the pairs $(\mathrm{A}, \mathrm{S})$ and $(\mathrm{B}, \mathrm{T})$ are each occasionally weakly compatible there exists $x, y \in X$ such that $A x=S x$ and $B y=T y$.

We assert that $A x=B y$. Otherwise by equation (i), we have

This gives

$$
\begin{gathered}
\phi\left\{\begin{array}{l}
M(A x, B y, t), M(A x, B y, t), M(A x, A x, t), \\
M(B y, B y, t), M(A x, B y, t), M(B y, A x, t)
\end{array}\right\} \geq 0 ; \\
\psi\left\{\begin{array}{l}
N(A x, B y, t), N(A x, B y, t), N(A x, A x, t), \\
N(B y, B y, t), N(A x, B y, t), N(B y, A x, t)
\end{array}\right\} \leq 0 .
\end{gathered}
$$

$$
\begin{aligned}
& \phi\left\{\begin{array}{l}
M(A x, B y, t), M(A x, B y, t), 1, \\
1, M(A x, B y, t), M(B y, A x, t)
\end{array}\right\} \geq 0 ; \\
& \psi\left\{\begin{array}{l}
N(A x, B y, t), N(A x, B y, t), 0, \\
0, N(A x, B y, t), N(B y, A x, t)
\end{array}\right\} \leq 0
\end{aligned}
$$

Using implicit relations $\left(\mathrm{F}_{1}\right)$ and $\left(\mathrm{F}_{4}\right)$, we get

$$
M(A x, B y, t) \geq 1 \text { and } N(A x, B y, t) \leq 0 \text {. }
$$

Hence $M(A x, B y, t)=1$ and $N(A x, B y, t)=0$.

Therefore, $\mathrm{Ax}=\mathrm{By}$ and so $\mathrm{Ax}=\mathrm{Sx}=\mathrm{By}=\mathrm{Ty}$.

Moreover, if there is another point $v \in X$, such that $A v=S v$, then using (i) we obtain

This gives

$$
\begin{gathered}
\phi\left\{\begin{array}{l}
M(A v, B y, t), M(A v, T y, t), M(S v, A v, t), \\
M(T y, B y, t), M(A v, B y, t), M(B y, A v, t)
\end{array}\right\} \geq 0 ; \\
\psi\left\{\begin{array}{l}
N(A v, B y, t), N(A v, T y, t), N(S v, A v, t), \\
N(T y, B y, t), N(A v, B y, t), N(B y, A v, t)
\end{array}\right\} \leq 0 .
\end{gathered}
$$

$$
\begin{gathered}
\phi\left\{\begin{array}{l}
M(A v, B y, t), M(A v, B y, t), M(A v, A v, t), \\
M(B y, B y, t), M(A v, B y, t), M(B y, A v, t)
\end{array}\right\} \geq 0 ; \\
\psi\left\{\begin{array}{l}
N(A v, B y, t), N(A v, B y, t), N(A v, A v, t), \\
N(B y, B y, t), N(A v, B y, t), N(B y, A v, t)
\end{array}\right\} \leq 0 .
\end{gathered}
$$

Thus 
Preeti Sengar, Suman Jain, Aklesh Pariya and V.H.Badshah

Using implicit relations $\left(\mathrm{F}_{1}\right)$ and $\left(\mathrm{F}_{4}\right)$, we get

$$
\begin{gathered}
\phi\left\{\begin{array}{l}
M(A v, B y, t), M(A v, B y, t), 1, \\
1, M(A v, B y, t), M(B y, A v, t)
\end{array}\right\} \geq 0 ; \\
\psi\left\{\begin{array}{l}
N(A v, B y, t), N(A v, B y, t), 0, \\
0, N(A v, B y, t), N(B y, A v, t)
\end{array}\right\} \leq 0 .
\end{gathered}
$$

$M(A v, B y, t) \geq 1$ and $N(A v, B y, t) \leq 0$.

Hence $M(A v, B y, t)=1$ and $N(A v, B y, t)=0$

Therefore $\mathrm{Av}=\mathrm{By}=\mathrm{Sv}=\mathrm{Ty}$.

Therefore $A v=B y$ and $w=A x=S x$ is the unique point of coincidence of the pair $(A, S)$.

By lemma 1.1, w is the only unique common fixed point of the pair (A, S).

Similarly, there exists a unique point $\mathrm{z} \in \mathrm{X}$ such that $\mathrm{z}=\mathrm{Bz}=\mathrm{Tz}$.

Suppose that $w \neq z$.Using (i), we have

$$
\begin{gathered}
\phi\left\{\begin{array}{c}
M(A w, B z, t), M(S w, T z, t), M(S w, A w, t), \\
M(T z, B z, t), M(A w, T z, t), M(B z, S w, t)
\end{array}\right\} \geq 0 ; \\
\psi\left\{\begin{array}{c}
N(A w, B z, t), N(S w, T z, t), N(S w, A w, t), \\
N(T z, B z, t), N(A w, T z, t), N(B z, S w, t)
\end{array}\right\} \leq 0 .
\end{gathered}
$$

Thus

This gives

$$
\begin{gathered}
\phi\left\{\begin{array}{c}
M(w, z, t), M(w, z, t), M(w, w, t), \\
M(z, z, t), M(w, z, t), M(z, w, t)
\end{array}\right\} \geq 0 ; \\
\psi\left\{\begin{array}{c}
N(w, z, t), N(w, z, t), N(w, w, t), \\
N(z, z, t), N(w, z, t), N(z, w, t)
\end{array}\right\} \leq 0 .
\end{gathered}
$$

$$
\begin{gathered}
\phi\left\{\begin{array}{l}
M(w, z, t), M(w, z, t), 1, \\
1, M(w, z, t), M(z, w, t)
\end{array}\right\} \geq 0 ; \\
\psi\left\{\begin{array}{l}
N(w, z, t), N(w, z, t), 0, \\
0, N(w, z, t), N(z, w, t)
\end{array}\right\} \leq 0
\end{gathered}
$$

Using implicit relations $\left(\mathrm{F}_{1}\right)$ and $\left(\mathrm{F}_{4}\right)$, we get

$\mathrm{M}(\mathrm{w}, \mathrm{z}, \mathrm{t}) \geq 1$ and $\mathrm{N}(\mathrm{w}, \mathrm{z}, \mathrm{t}) \leq 0$.

Hence $M(w, z, t)=1$ and $N(w, z, t)=0$.

Therefore $\mathrm{w}=\mathrm{z}$ is the unique common fixed point of $\mathrm{A}, \mathrm{B}, \mathrm{S}$ and $\mathrm{T}$.

Corollary 2.1. The result of Theorem 2.1 remains true if we replace the inequality (i) of Theorem 2.1 by any one of the following conditions:

(i)

$$
\begin{aligned}
& M(A x, B y, t) \geq \phi\left(\min \left\{\begin{array}{c}
M(S x, T y, t), M(S x, A x, t), M(T y, B y, t) \\
M(A x, T y, t), M(B y, S x, t)
\end{array}\right\}\right) \\
& N(A x, B y, t) \geq \psi\left(\max \left\{\begin{array}{c}
N(S x, T y, t), N(S x, A x, t), N(T y, B y, t) \\
N(A x, T y, t), N(B y, S x, t)
\end{array}\right\}\right)
\end{aligned}
$$

for all $\mathrm{x}, \mathrm{y} \in \mathrm{X}$, where $\phi, \psi:[0,1] \rightarrow[0,1]$ is increasing and continuous function such that $\phi(\mathrm{t})>\mathrm{t}$ and $\psi(\mathrm{t})<\mathrm{t}$ for all $\mathrm{t} \in(0,1)$

(ii)

$$
\int_{0}^{M(A x, B y, t)} \varphi(t) d t \geq \phi\left(\int_{0}^{\min \left\{\begin{array}{c}
M(S x, T y, t), M(S x, A x, t), M(T y, B y, t) \\
M(A x, T y, t), M(B y, S x, t)
\end{array}\right.} \varphi(t) d t\right)
$$


Common Fixed Points of Occasionally Weakly Compatible in Intuitionistic Fuzzy Metric Space

and

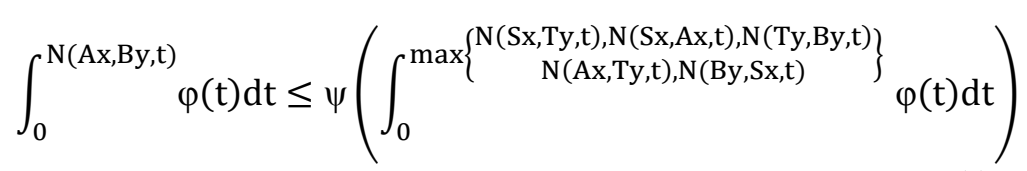

where $\phi, \psi:[0,1] \rightarrow[0,1]$ is increasing and continuous function such that $\phi(\mathrm{t})>\mathrm{t}$ and $\psi(\mathrm{t})$ $<\mathrm{t}$ for all $\mathrm{t} \in(0,1)$ and $\varphi: \mathrm{R}^{+} \rightarrow \mathrm{R}^{+}$is a summable, Lebesgue integrable function satisfies 0 $<\int_{0}^{\varepsilon} \varphi(\mathrm{s}) \mathrm{ds}<1$, for all $0<\varepsilon<1$.

By setting $\mathrm{A}=\mathrm{B}$ in Theorems 2.1, we derive the following corollary for three mappings.

Corollary 2.2. Let $\mathrm{A}, \mathrm{S}$ and $\mathrm{T}$ be three self-mappings of an intuitionistic fuzzy metric space $(X, M, N, *, \diamond)$ satisfying the following conditions:

for any $\mathrm{x}, \mathrm{y} \in \mathrm{X}, \phi, \psi \in \mathrm{M}_{6}$ and for all $\mathrm{t}>0$,such that

$$
\begin{array}{r}
\phi\left\{\begin{array}{l}
M(A x, A y, t), M(S x, T y, t), M(S x, A x, t), \\
M(T y, A y, t), M(A x, T y, t), M(A y, S x, t)
\end{array}\right\} \geq 0 ; \\
\psi\left\{\begin{array}{l}
N(A x, A y, t), N(S x, T y, t), N(S x, A x, t), \\
N(T y, A y, t), N(A x, T y, t), N(A y, S x, t)
\end{array}\right\} \leq 0 .
\end{array}
$$

If the pairs (A, S) and (A, T) are each occasionally weakly compatible, then $\mathrm{A}, \mathrm{S}$ and $\mathrm{T}$ have a unique common fixed point.

Finally, by setting $\mathrm{A}=\mathrm{B}$ and $\mathrm{S}=\mathrm{T}$ in Theorems 2.1 , we get the following corollary.

Corollary 2.3. Let A, S be two self-mappings of an intuitionistic fuzzy metric space (X, $\mathrm{M}, \mathrm{N}, *, \diamond)$ satisfying the following conditions:

for any $\mathrm{x}, \mathrm{y} \in \mathrm{X}, \phi, \psi \in \mathrm{M}_{6}$ and for all $\mathrm{t}>0$,such that

$$
\begin{array}{r}
\phi\left\{\begin{array}{l}
M(A x, A y, t), M(S x, S y, t), M(S x, A x, t), \\
M(S y, A y, t), M(A x, S y, t), M(A y, S x, t)
\end{array}\right\} \geq 0 \\
\psi\left\{\begin{array}{l}
N(A x, A y, t), N(S x, S y, t), N(S x, A x, t), \\
N(S y, A y, t), N(A x, S y, t), N(A y, S x, t)
\end{array}\right\} \leq 0 .
\end{array}
$$

If the pairs (A, S) occasionally weakly compatible, then $\mathrm{A}, \mathrm{S}$ have a unique common fixed point.

Remark 1.2. The purpose of this paper is to prove some general common fixed point theorem for occasionally weakly compatible mappings satisfying implicit relations in intuitionistic fuzzy metric space which generalizes several results from the literature. Our results generalize several fixed point theorems in following respects.

(a) The class of spaces is widened from the class of metric space to the class of intuitionistic fuzzy metric spaces.

(b) The class of implicit relations is also enriched significantly as it requires merely one condition to satisfy.

(c) The condition on completeness/compactness of the space is completely relaxed.

(d) The condition of property (E.A.) / weak compatibility is weakened to occasionally weakly compatible. 
Preeti Sengar, Suman Jain, Aklesh Pariya and V.H.Badshah

(e) The condition of surjectivity of the mappings is completely relaxed. Consequently the condition of the required containment of the ranges of the involved mappings is not essential.

(f) The condition of continuity of the involved mappings is also relaxed.

\section{REFERENCES}

1. C.Alaca, D.Turkoglu and C.Yildiz, Fixed points in intuitionistic fuzzy metric spaces, Chaos, Solitons \& Fractals, 29 (2006) 1073-1078.

2. C.Alaca, I.Altun and D.Turkoglu, On compatible mappings of type (I) and (II) in intuitionistic fuzzy metric space, Commun. Korean Math. Soc., 23(3) (2008) 427446.

3. M.A.Al-Thagafi and N.Shahzad, Generalized I Non-expansive self maps and invariant approximations, Acta Mathematica Sinica, 24(5) (2008), 867-876.

4. M.A.Al-Thagafi and N.Shahzad, A note on occasionally weakly compatible maps, Int. Jour. Math. Anal., 3(2) (2009) 55-58.

5. A.Aliouche, Common fixed point theorems via in implicit relation and new properties, Soochow Journal of Mathematics, 33(4) (2007) 593-601.

6. K.Atanassov, Intuitionistic fuzzy sets, Fuzzy Sets and Systems, 20 (1986) 87-96.

7. S.Banach, Sur les operations dans les ensembles abstraites et leur applications aux integrals, Fund. Math., 3 (1922) 133-181.

8. M.Edelstein, On fixed and periodic points under contractive mappings, J. London Math. Soc., 37 (1962) 74-79.

9. M.Grabiec, Fixed points in fuzzy metric spaces, Fuzzy Sets and Systems, 27 (1988) 385-389.

10. M.Imdad, J.Ali and V.Popa, Impact of OWC property on common fixed point theorems for expansive mappings, Filomat, 25(2) (2011) 79-89.

11. G.Jungck and B.E.Rhoades, Fixed point theorems for Occasionally Weakly Compatible mappings, Fixed Point Theory, 7(2) (2006) 287-296.

12. I.Kramosil and J.Michalek, Fuzzy metric and statistical metric space, Kybernetica, 11 (1975) 326-334.

13. S.Manro, S.S.Bhatia and S.Kumar, Common fixed point theorems for WC maps satisfying common (E.A) property in Intuitionistic fuzzy metric spaces using implicit relation, Journal of Advanced Studies in Topology, 3(2) (2012) 38-44.

14. S.Manro, S.S.Bhatia and S.Kumar, Common fixed point theorems in intuitionistic fuzzy metric spaces using implicit relation, Journal of Advanced Research in Applied Mathematics, 6(1) (2014) 16-26.

15. J.S.Park, Y.C.Kwun and J.H.Park, A fixed point theorem in the intuitionistic fuzzy metric spaces, Far East J. Math. Science, 16 (2005) 137-149.

16. A.Sindersiya, A.Pariya, N.Gupta and V.H.Badshah, Common fixed point theorem in complex valued metric spaces satisfying rational inequality, Annals of Pure and Applied Mathematics, 12 (2) (2016) 137-142.

17. A.Sugandhi, S.K.Tiwari and A.Pariya, Common fixed point theorems in intuitionistic fuzzy symmetric spaces for occasionally weakly compatible maps satisfying contractive condition of integral type, Annals of Pure and Applied Mathematics, 11(2) (2016)11-19.

18. L.A.Zadeh, Fuzzy sets, Information and Control, 8 (1965) 338-353. 